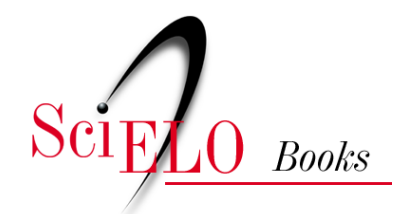

\title{
EDUFU
}

\section{Jogos corporais em sala de aula}

\author{
Nara Keiserman
}

KEISERMAN, N. Jogos corporais em sala de aula. In: FLORENTINO, A., and TELLES, N., eds. Cartografias do ensino do teatro [online]. Uberlândia: EDUFU, 2008, pp. 221-231. ISBN 978-857078-518-3. https://doi.org/10.7476/9788570785183.0023.

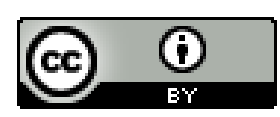

All the contents of this work, except where otherwise noted, is licensed under a Creative Commons Attribution 4.0 International license.

Todo o conteúdo deste trabalho, exceto quando houver ressalva, é publicado sob a licença Creative Commons Atribição 4.0.

Todo el contenido de esta obra, excepto donde se indique lo contrario, está bajo licencia de la licencia $\underline{\text { Creative Commons }}$ Reconocimento 4.0. 


\section{JOGOS CORPORAIS EM SALA DE AULA}

Nara Keiserman

Dentro do imenso repertório de Jogos Teatrais, há aqueles em que o Movimento é usado pelo aluno como principal meio de expressão, em que se pode dizer que é o corpo que fala. Estes jogos favorecem a aquisição e/ou aprimoramento de diferentes qualidades, referentes tanto a aspectos propriamente físicos, como outras de caráter social e mesmo psicológico.

Pensando a Educação como instrumento efetivo para o desenvolvimento harmonioso da pessoa por inteiro e acompanhando o pensamento de Moshe Feldenkrais, em seu livro Consciência pelo Movimento, credito ao Movimento um importante papel neste contexto educacional. Segundo o autor, quando estamos acordados lançamos mão dos quatro componentes da vigília, que são as sensações, os sentimentos, o pensamento e o movimento. De acordo com a tarefa praticada, estes componentes estão mais ou menos ativados, mas a falta total de um deles é sintoma garantido de doença ou desequilíbrio. Feldenkrais chama de ATENÇÃO* (escrito assim, com maiúscula e asterisco) o estado almejado em que os componentes da vigília estão em perfeito equilíbrio, possibilitando ações efetivas e harmoniosas - em outras palavras, o estado de componentes que favorece uma vida feliz e saudável. No caso do adulto, o objetivo do trabalho é restabelecer o fluxo de comunicação entre aqueles quatro componentes. Quando se trata da criança, o objetivo é oferecer oportunidades de Jogo para que ela se mantenha em contato pleno com suas sensações (advindas dos cinco sentidos), seus sentimentos (que não podem ser bloqueados), seu pensamento (fértil, espontâneo, inteligente), por meio da ativação e expressão através do Movimento.

Para que haja um bom aproveitamento das propostas de Jogos Corporais listados abaixo, é preciso algumas palavras sobre o professor que vai propô-los e o modo como isso será feito.

\section{O professor e a aula}

O professor é um guia, um orientador. É um parceiro dos jogos que vai propor, em que exerce a função de dar indicações e sugerir caminhos. Não aponta modelos a 
serem seguidos, mas oferece oportunidades de encontro de cada um consigo mesmo. Esse professor é um parceiro de seus alunos e deve, mais do que tudo, amar e respeitar os seus corpos e o seu próprio, para poder observar atentamente as suas expressões, manifestas ou escamoteadas, ao mesmo tempo em que sente o seu próprio corpo, que certamente também fala uma língua que os alunos entendem e com a qual dialogam mesmo no silêncio. Se o professor pretende que os alunos joguem espontaneamente, que sejam capazes de exercer plenamente suas percepções, ele próprio deve ser capaz de fazê-lo. Isso é muito claro em outras matérias, mas no Teatro, às vezes, se esquece que é preciso saber fazer para saber ensinar.

O professor é aquele que vê todos os alunos, que sabe ler as suas mensagens corporais, que sabe ouvir, que sabe tocar nos seus corpos nos momentos necessários, que reconhece quando deve falar ou silenciar. O professor é aquele que sente.

Há alguns aspectos ou princípios que organizam a prática dos Jogos Corporais, que serão alterados pelo professor de acordo com as circunstâncias em que trabalha, e que convém que os alunos conheçam logo na primeira aula. São eles: dar preferência ao uso de roupas confortáveis, que não impeçam os movimentos e que possam sujar e aos pés descalços, para um melhor contato com o chão e a libertação dos pés do domínio torturante dos sapatos - isso vale também para o professor. Não há um jeito certo de realizar os jogos propostos, já que cada um deles possibilita muitos e muitos modos de execução possíveis, criativos, originais, o que significa que de nada serve espiar os colegas e que a avaliação do professor não vai se guiar por critérios de certo ou errado. As dúvidas quanto à compreensão da proposta do Jogo devem ser feitas antes de se iniciar a jogar e o professor só vai responder aquilo que considerar imprescindível para que o aluno dê início ao seu movimento. Uma idéia vaga do que é para fazer é suficiente para começar. As instruções dadas durante o jogo vão suprindo as dúvidas que possam gerar insegurança, ao mesmo tempo em que ajudam o aluno a manter-se no jogo, ou seja, a pensar no que faz enquanto faz - uma das principais metas do trabalho com os Jogos Corporais. Os alunos não devem olhar para o professor durante o Jogo, de que este participa apenas como voz e isso porque há um estado almejado de imaginação ficcional que o próprio aluno estabelece e de que o professor não faz parte.

Cabe, portanto, ao professor, ser econômico no enunciado da proposta, de modo a não antecipar ou dar pistas sobre como realizá-la; nas instruções dadas durante a sua realização, orientar os alunos no sentido de encaminhar o seu percurso em direção ao objetivo da proposta e a descoberta de uma linguagem pessoal de expressão pelo movimento; ter como critério para a avaliação os objetivos (que para isso devem ser claros, tanto para o professor quanto para os alunos) e o que vai avaliar é em que medida o grupo os alcançou, tendo o cuidado de não expor as fraquezas ou dificuldades individuais, mas sempre salientando os aspectos positivos do que foi realizado.

\section{Jogos corporais}

A seguir, uma listagem de propostas de Jogos Corporais que admitem muitas variações, a serem selecionados pelo professor de acordo com as necessidades de seus alunos e condições em que trabalha, como dimensões da sala, duração da aula, 
organização curricular, faixa etária, número e experiência dos alunos, entre outras. Certamente, todos estes aspectos interferem no resultado obtido.

Os Jogos, pontos de partida para a elaboração de muitos outros, estão organizados de acordo com o foco principal das propostas e assim denominados: Percepção Sensorial, Partes do Corpo, Locomoção e Espaço - sem esquecer que, em todos eles, o Movimento é o canal privilegiado de expressão e realização pessoal.

\section{Percepção Sensorial}

Aqui se trabalham os Sentidos e sua relação com movimento em duas direções: com que movimentos se podem apreender as sensações e que movimentos esta apreensão vai gerar.

\section{Audição}

Esta proposta não deve ser anunciada previamente. Os alunos devem estar numa posição confortável, em atitude aquietada, serena, de olhos fechados. O professor deve saber o que propor para colocar os alunos neste estado, de atenção serena, de disposição sem alarido. Ir indicando cada etapa, dando o tempo necessário para a sua realização - é preciso que o professor tenha essa percepção do grupo. Pedir que os alunos abram os olhos quando começarem a se deslocar no espaço caso isso não ocorra espontaneamente, o professor poderá indicar.

1) Ouvir o som que vem de mais longe. 2) Imaginar quem ou o que produz este som (a imagem do som, a fonte sonora). 3) Ouvir o som que vem de mais perto, mas fora da sala de aula. Visualizar a fonte. 4) Há algum som vindo de um ponto intermediário, entre o mais distante e o mais próximo? Ouvir e imaginar a fonte. 5) Para cada um dos sons imaginar mais de uma fonte. 6) Movimentar-se conforme um dos sons que vem de fora. 7) Cantar uma música mentalmente e imaginar que ela percorre o corpo por dentro. 8) Ir movimentando cada parte do corpo por onde a música passa. Como se fosse o movimento que produzisse o som. 9) Alternar (por indicação do professor ou a critério do aluno) as duas atitudes de resposta ao som de fora e música de dentro, sempre com movimentos - que podem ser muito pequenos. 10) Reagir com movimento aos sons da sala, que podem ser produzidos por CDs, instrumentos musicais ou outros. 11) Alternar: quando há som dentro da sala, movimentar-se; quando há silêncio, movimentar-se de acordo com a música interna; por indicação ou não, ouvir os sons de fora, sem movimento.

Como na proposta anterior, os alunos devem estar aquietados fisicamente e com o pensamento vivo. Não há necessidade de explicações prévias e a posição inicial é deitada.

1) Pedir aos alunos que observem os únicos movimentos existentes no seu corpo no momento em que eles não estão se movimentando, que são os da respiração. 2) Nela, observar: a) o contato do corpo com o chão se modifica na inspiração e na expiração? b) onde, no corpo, sente que chega o movimento da respiração? c) existe pausa entre os movimentos de inspiração / expiração? d) qual o tempo de cada movimento e da pausa? e) perceber que o peito, na inspiração, alarga-se lateralmente, sobe na direção do teto, e a pélvis como que pressiona o chão, a cintura afasta-se levemente do chão e o retorno destas partes do corpo, trazendo uma sensação de relaxamento, na expiração. 3) Imaginar um termômetro colocado dentro do peito, começando no 
pescoço e indo até a altura do umbigo. Imaginar que ao inspirar o mercúrio desce e na expiração sobe; e depois ao contrário, ao inspirar sobe e ao expirar desce. 4) Colocar movimento na respiração: ao inspirar, elevar qualquer parte do corpo, na expiração executar movimentos descendentes e, nas pausas, não se movimentar. A duração de cada movimento e das pausas deve corresponder exatamente aos tempos da respiração. 5) Ao expirar, deixar que produza um som, que poderá ser de S ou F. 6) Substituir este som pelos sons dos fonemas que compóem o seu nome. Criar movimentos para cada som, sem mais a preocupação com o seu desenho no espaço (ascendente ou descendente). Buscar variedade na emissão dos sons (duração, força, altura, timbre) e que os movimentos tenham alguma relação com eles. Compor a seqüência de sons e movimentos até o nome todo. 7) Alternar: realizar apenas os sons, visualizando os movimentos; realizar apenas os movimentos, ouvindo os sons mentalmente. Decorar as duas seqüências, de sons e movimentos. 8) Andar pela sala, parando a cada pessoa que encontrar e se apresentar com este seu novo nome (sem o movimento). "Falar" e ouvir e só então andar, para um novo encontro. Repetir até que cada um tenha passado por todos. 9) Em roda, em pé. Cada um faz o seu movimento, ouvindo o som mentalmente. Os outros observam tentando associar com o som que ouviram. Em seguida, repetir o movimento observado, todos juntos. É o que se chama de imitação eco. 10) Retomar a sua própria seqüência, modificando-a em função do que viu, ouviu e realizou. 11) Novamente na roda, cada um realiza a sua seqüência de sons e movimentos, com imitação eco.

\section{Visão}

Dividir os alunos em dois grupos. Um observa e o outro joga. Os jogadores ficam de costas para o local do jogo.

1) O primeiro aluno se coloca no espaço e faz uma pose. 2) O próximo, do grupo de jogadores observa-o com a intenção de reproduzir a pose com o máximo de fidelidade. Depois de um certo tempo, que deverá ser curto, o primeiro aluno desfaz a pose e o segundo a reproduz. 3) Vem o terceiro, observa a pose do segundo. Este desfaz e aquele a executa. E assim por diante. Quando o último aluno do grupo de jogadores a fizer, todos se colocam em linha e cada um faz a sua pose. 4) O grupo de observadores vai apontar as alterações que foram feitas na pose original. Trocar as funções.

É importante que o aluno que observa o faça sem imitar, de modo que sua capacidade de ver e reter o que viu possa ser exercitada.

\section{Tato}

Anunciar aos alunos que será feito um trabalho de percepção sensorial através do tato - sentido que só é ativado quando tocamos um objeto ou uma pessoa; quando milhares de células que entram em ação para nos informar se algo é quente ou frio, áspero ou macio, seco ou úmido. Assim, é nisto que estará a sua atenção, de modo que ao tocar o objeto deve ser evitado o pensamento comumente imediato de pensar na sua utilidade. O pensamento que acompanhará todos os movimentos se dá em função das sensações que ele desperta. Deve ser evitado a todo custo agir com uma caneta na mão como quem escreve no ar - por exemplo. Os movimentos que a caneta vai trazer para o aluno se dão devido a sua forma, textura, densidade. 
O jogo:

Todos estarão sentados em roda enquanto o professor conversa sobre o que foi explicitado acima. Cada aluno vai lembrar dos objetos que tem na sua bolsa e selecionar um deles para o Jogo. De maneira tranqüila e sem comentários verbais cada um vai apanhar este objeto ou outro que chame mais sua atenção.

1) Colocar o objeto no centro da roda e voltar a sentar. 2) Observar os objetos à medida que vão sendo colocados, observando suas características, e evitando pensar neles por seu nome. Voltando ao mesmo exemplo, não pensar "caneta”, mas sim objeto fino, transparente etc. $O$ professor chama a atenção do aluno para o quanto a visão e a experiência podem suprir o próprio toque. Basta olhar um objeto para que se saiba se ele é flexível ou não, áspero ou não, e até mesmo para sentir o seu aroma e paladar. 3) Fechar os olhos e colocar as mãos em concha, à frente do corpo. O professor vai distribuir os objetos, colocando-o nas mãos de cada aluno. 4) Assim que o sentir nas mãos, iniciar a pesquisa sensorial do objeto, conferindo pelo tato aquilo que a visão já havia informado. Experimentar o objeto em várias partes do corpo, observando as diferentes percepções. Experimentar equilibrar o objeto em diferentes partes do corpo, de modo a prescindir das mãos. 5) Colocar o objeto bem perto dos olhos e abri-los. Movimentar-se a partir das indicações de ter o objeto no corpo, perto do corpo, longe do corpo - sem e com deslocamento no espaço. 6) Seguir a instrução: eu movimento o objeto / o objeto me movimenta. 7) Trocar de objeto com a pessoa que estiver mais próxima, fazendo deste momento um acontecimento de troca efetiva. 8) Movimentar-se com o novo objeto. 9) Nova troca, nova movimentação. Instruir o aluno para que permita que cada novo objeto traga novos movimentos. 10) Colocar-se em duplas e comunicar-se através dos objetos. Indicar que se trata de um jogo entre quatro parceiros, em que dois são objetos. 11) A dupla seleciona um dos objetos e segue seu diálogo através deste objeto. 12) Trocar o objeto, apanhando o que havia sido deixado de lado. 13) Separar-se do par, seguindo com o objeto que era inicialmente do outro. 14) Nova dupla, mesmo procedimento. 15) Trocar de objeto até que tenha nas mãos o seu objeto, aquele que apanhou na sua bolsa. Instruir para a diferença entre olhar aberto para o jogo enquanto não encontrou o seu objeto e, ao contrário, o olhar com foco definido no objeto quando tiver encontrado o seu. 16) Assim que tiver o seu objeto nas mãos, movimentar-se em função dele. 17) Para finalizar, pode-se pedir que simplesmente devolvam o objeto na bolsa, ou que o coloquem no centro, voltando para a roda. Neste caso: olhar todos os objetos, identificando aqueles com que trabalhou e observar o novo olhar que pode ter para estes objetos e eventualmente até mesmo para os outros. O que mudou não foi o objeto, evidentemente, mas sim o olhar.

\section{Paladar e Olfato}

Cada aluno traz um objeto de comer, devidamente embalado (já que vai ser jogado, manuseado etc.), e outro que tenha um cheiro que considere especial. O ponto de partida é o mesmo usado nas propostas para o aprimoramento do Tato com foco nos objetos. Pode-se fazer em duas etapas, sendo a primeira com os objetos de cheiro, de modo que este determine os movimentos executados. Para o objeto de comer, a partir do momento em que cada um está com o seu objeto nas mãos, os alunos vão ser orientados para: 
1) Visualizar o objeto por dentro da embalagem. 2) Sentir seu gosto só de o ter nas mãos e olhar. 3) Colocá-lo muito perto dos olhos e ir, lentamente, abrindo a embalagem, ouvindo o barulho que isto produz, apreciando cada movimento que faz para isso. 4) Cheirar o objeto. 5) Sentir seu gosto só de o ter nas mãos, olhar e cheirar. 6) Finalmente, quando não agüentar mais, colocá-lo na boca. 6) Andar pela sala, mostrando o seu objeto e partilhando-o com os outros. 7) Devolver o objeto, ou o que sobrou dele, ao centro da sala. 8) Olhar para cada objeto sentindo seu sabor e aroma e dançar a sensação. 9) Sem olhar para os objetos, dançar a sensação.

\section{Partes do Corpo:}

O objetivo principal é dar oportunidade ao aluno de mobilizar as diferentes partes do corpo, numa idéia de isolamento (o aluno ser capaz de movimentá-las de forma independente) assim como de composição, em que o movimento de uma parte determina as posições ou movimentos de outras. Entram no jogo os conceitos de repercussão e fluência. O aluno é orientado para permitir que o movimento iniciado numa parte do corpo repercuta no corpo inteiro e ainda que observe o modo como o movimento se espalha, fluindo pelo corpo inteiro.

É claro que a percepção e a consciência do corpo aparecem aqui como causa e conseqüência, ou seja, elas são simultaneamente favorecedoras do resultado alcançado na execução da proposta, como se beneficiam dela.

Estes Jogos permitem que se faça analogias entre as partes do corpo, favorecendo uma compreensão de sua estrutura. É fácil para os alunos perceberem seu corpo como formado por três volumes empilhados: a cabeça (uma espécie de aquário), o peito (caixa torácica) e a pélvis (bacia), os três unidos por um fio que é a coluna. Do volume de cima saem dois "penduricalhos", os braços, e do volume de baixo outros dois, as pernas. Há duas cinturas: a de cima une o aquário à caixa, e a de baixo, a caixa à bacia. Os volumes não se partem ao meio, seus movimentos são compactos: vão inteiros para cima, para baixo, para frente, para trás, para a direita e para a esquerda, enquanto os penduricalhos podem ser revirados em todas as direções de forma independente uns dos outros.

As propostas seguem o seguinte padrão:

Movimentar-se com o foco em tal parte do corpo, iniciando pela posição deitada até chegar a ficar em pé, seguindo com deslocamentos no espaço. A realização é de início individual, seguindo em duplas. Os dois alunos podem estar colocados à distância, ou próximos um do outro, por muito pouco tempo, trocando de par constantemente - o que obriga a rápidas adaptações de resposta corporal - ou permanecendo por um tempo maior, de modo a aprofundar a relação. Esta deve ser de diálogo entre as partes do corpo, de comunicação efetiva. A cada troca de par deve haver uma mudança nas qualidades dos movimentos, considerando que há um estímulo vindo do par, a quem a resposta corporal será sempre única.

A parte do corpo que está com o foco pode ser determinada pelo professor ou selecionada pelo aluno. Nas duplas, os dois podem ou não estar se comunicando com a mesma parte do corpo. Pode ser feito em grupos maiores. Pode-se ter mais de um foco, por exemplo: um na parte alta e outro na parte baixa do corpo, considerando a cintura a linha média, ou um para cada lado do corpo, direita e esquerda. 


\section{Locomoção}

A base para os Jogos Corporais de Locomoção pode ser encontrada no livro La expresión corporal y el niño, de Patrícia Stokoe. Ali, ela se refere aos Movimentos Fundamentais de Locomoção, identificando cinco deles, ordenados de acordo com a sua circunscrição espacial: arrastar-se, em que o corpo está todo na linha do chão; engatinhar, em que o tronco está fora do chão, englobando as locomoções sobre joelhos e sobre os glúteos; andar, quando nos encontramos sobre os dois pés; correr, em que se alternam sucessivamente pé e outro sobre o chão; e saltar, em que a ênfase está em sair do chão, em ganhar o espaço aéreo. Cada um destes movimentos de Locomoção admite muitas variações, de acordo com: a postura de base, ou seja, o modo como o corpo se coloca o espaço para iniciar o movimento, e que será mantida durante sua realização; a parte do corpo que conduz o movimento; o modo como as partes do corpo vão se movimentando de forma simultânea ou sucessiva; os graus de energia empregados nas diferentes partes do corpo; o desenho no espaço; o andamento adotado, por exemplo.

Os movimentos podem ser sugeridos aos alunos na sua ordenação espacial, do chão para o ar ou vice-versa, ou indicar a sua realização por contraste, fazendo com que o corpo tenha que se organizar para fazer mudanças bruscas e repentinas, como em: arrastar-se e andar; engatinhar e correr; andar e saltar. Pode-se ainda propor uma realização em que cabe aos alunos organizar a sua seqüência, selecionando a ordem e o tempo de permanência em cada movimento, de acordo com sua imaginação e impulso corporal.

Convém conversar com os alunos sobre os movimentos de Locomoção, o que diferencia uns dos outros, antes de propor os Jogos.

O movimento de andar pode ser assim trabalhado: 1) $O$ professor vai indicando uma por uma as partes do corpo envolvidas no andar, solicitando dos alunos uma atitude de percepção em relação ao seu modo de atuação. Por exemplo: o que fazem os dedos dos pés? Movimentam-se juntos ou separados? Qual o tamanho do passo? Para onde apontam os pés? Quando e como se dá a transferência de peso de um pé para o outro? 2) O professor vai indicando uma por uma as articulações envolvidas no andar, pedindo aos alunos que exagerem no seu movimento e depois que as anulem. Ao chegar à articulação que une a coxa ao quadril, o aluno descobrirá que é impossível andar. 3) O professor sugere variações nas dimensões e no andamento do passo, do movimento dos braços, da cabeça, da pélvis, do tronco. 4) Cada aluno observa atentamente seu modo de andar até descobrir qual o seu traço mais forte e evidente. Vai aos poucos exagerando nisso até ter uma caricatura do seu próprio andar. 5) Observar o andar de um colega, sem que ele perceba e sem modificar o seu próprio, que possivelmente está sendo observado por outro. Ao sinal do professor, transformar imediatamente o seu andar, reproduzindo o do colega observado. Descobrir aí, então, a sua marca mais forte e ir, aos poucos, exagerando até a caricatura. Cada um vai observando os demais, sem modificar o que está fazendo, tentando reconhecer-se no andar do outro. Isto não deve ser revelado ou apontado, a não ser pelo próprio aluno imitado que assim o desejar, manifestando-se espontaneamente a respeito. 


\section{Espaço:}

É considerado nas categorias de Espaço Interno ou Pessoal, Espaço Parcial e Espaço Total ou Global.

Espaço Interno ou Pessoal é aquele que se ocupa pelo simples fato de existir. Convém conversar com os alunos sobre isso, sobre o ar que se desloca para que se possa, simplesmente, estar aqui, ali, acolá. É uma ótima oportunidade para se conversar também sobre a pele, lembrando que ela é o maior órgão do corpo humano e responsável pela sensibilidade tátil, realizando várias e complicadas funções como proteção, manutenção da temperatura, defesa imunológica. É a pele que possibilita a troca entre o mundo interno e o externo, definindo o desenho de cada pessoa, seu perfil, sua silhueta.

Espaço Parcial é o que ocupamos sem locomoção, sem deslocamento. Neste caso, predominam os gestos, que são os movimentos que executamos no ar, ocupando o espaço à nossa volta. Seu desenho é basicamente retilíneo ou arredondado. Conforme Rudolf Laban, em seu livro Domínio do Movimento, significa o uso do espaço direto ou indireto, de sua ocupação em linhas retas ou sinuosas.

Espaço Total ou Global é aquele para o qual não há limites, e sua ocupação pode ser também considerada como direta ou indireta. Pensando a ocupação ou deslocamento do espaço em relação a um objetivo (objeto ou pessoa), as possibilidades são as de aproximar-se, afastar-se ou rodeá-lo.

Como no caso dos Jogos de Locomoção, convém aqui esclarecer os alunos sobre o que vai ser trabalhado. A proposta pode ser indicada já com os alunos na posição inicial.

Jogos:

Espaço Interno

1) Posição inicial: deitados no chão, com as pernas estendidas e afastadas naturalmente, os braços também estendidos ao longo do corpo. Visualizar o contorno do corpo, percebendo o seu desenho, o quanto de ar foi deslocado para dar espaço a ele, a marca deixada no chão se este fosse de areia. Visualizar o corpo conforme a estrutura já mencionada: três volumes unidos e seus penduricalhos, as duas cinturas. 2) Dobrar os joelhos, colocando os pés no chão e repetir a visualização, observando o que se modificou: quais as partes que encostam agora no chão, como algumas afundam mais do que antes e do que outras. 3) Tirar os pés do chão, levando as coxas em direção ao peito e repetir a visualização, com os mesmos pontos de observação. 4) Cada um vai elaborando outras posições, e em cada uma delas, repetir o exercício de visualização e percepção, respondendo-se: como está o desenho do meu corpo? Como ele está apoiado: no chão, no ar, sobre si mesmo? Estão próximos ou afastados os volumes e seus apêndices? Os movimentos que levam de uma posição a outra devem ser simples e contínuos, só interrompidos quando a posição parecer, ao aluno, interessante. 5) Organizar a seqüência de posições e movimentos de modo que cada vez vá ficando com um número menor de apoios sobre o chão, até finalmente ficar em pé. Cada posição ou pose pode ser associada a uma atitude de expansão ou recolhimento; de espalhar ou recolher; de dar ou tomar; de adesão ou resistência. Pedir aos alunos que identifiquem a sua atitude. 6) Andando, e ao sinal do professor, formar duplas ou grupos ao acaso. Apoiar-se um no outro formando uma pose, em que se permanece para realizar a mesma pesquisa anterior: 
o desenho dos dois corpos juntos, sua silhueta, o recorte que fazem no espaço, como estão apoiados, um no outro, no próprio corpo, no ar e a atitude. Importante ajudar o aluno a perceber a diferença entre encostar e apoiar, e que nenhuma das duas ações é a de empurrar. 7) Em grupos de quatro ou cinco. Um aluno se coloca numa pose. Outro se apóia nele, servindo de apoio para o próximo e assim por diante. Realizar a mesma pesquisa. $\mathrm{O}$ primeiro sai do seu lugar, sem que a pose já formada se altere e vai se apoiar no último. O que foi o segundo sai do seu lugar e se apóia sobre o primeiro e assim por diante até que todos estejam numa nova posição. Nova pesquisa. E assim por diante.

\section{Espaço Parcial}

Considera-se a possibilidade de movimentos em que o desenho do corpo todo adquire diferentes formas, quais sejam: uma forma arredondada, a "bola", em que as partes afastadas do corpo quando estamos na posição ereta se aproximam; a "seta", em que predominam as linhas retas e as partes do corpo se afastam, e o "parafuso", em que as partes do corpo apontam para várias direções de forma sucessiva ou simultânea. Todos esses são desenhos trabalhados no Espaço Parcial, ou seja, sem locomoção, de forma individual, em dupla ou em grupos maiores. É necessário explicar aos alunos do que se tratam esses desenhos antes de pedir que se coloquem na posição deitada.

\section{O jogo:}

1) Levantar descrevendo um parafuso, que vai de baixo para cima, até que fique na posição de pé. 2) Movimentar-se em bola. 3) Movimentar-se em seta. 4) Movimentar-se em parafuso. 5) Colocar-se rapidamente em poses com a forma que o professor vai solicitando. 6) Colocar-se numa pose em parafuso, movimentar-se em bola até chegar à outra pose em parafuso. 7) Colocar-se numa pose em seta, movimentar-se em bola até chegar à outra pose em seta. E assim por diante, até que se tenha proposto todas as combinações possíveis.

Quando feito em duplas ou grupos maiores, instruir os alunos para a idéia de, ao realizar a forma, ir dando espaço para o movimento do outro, ao mesmo tempo em que, com seus movimentos, interfere no espaço oferecido.

\section{Espaço Total}

1) Em grupos de quatro, os alunos se colocam numa formação espacial em losango, todos voltados para a mesma direção. Os movimentos que executam, com locomoção, são liderados pelo que está à frente. Quando este mudar a direção, executando um quarto de volta ou meia volta, o que passará a estar na frente vai guiar os movimentos. $\mathrm{O}$ importante é que se mantenham as distâncias iniciais estabelecidas entre eles de que não se perca o desenho do losango.

2) Locomover-se em espiral, ao redor de um ponto imaginário, do eixo menor para o maior, até abarcar a sala toda, e voltando na direção inversa até retornar ao ponto de partida. É a própria trajetória que vai determinar o movimento de locomoção, o andamento, a parte do corpo que lidera, o modo como o movimento flui pelo corpo etc. Pode ser feito em duplas, em que um tem a função de eixo, ou em grupos maiores, em que um faz o eixo ou todos se locomovem simultaneamente, ao redor uns dos outros. 
3) Estabelecer um ponto de atração, imaginário ou real. Ir até ele em linha reta. Ao chegar lá, alguma coisa estabelece um impulso de repulsão, que faz a pessoa afastar-se em linha sinuosa até um outro ponto qualquer do espaço. Mesma coisa, com atração e repulsão em linha reta; em linha sinuosa; atração em linha sinuosa e repulsão em linha reta.

\section{Considerações finais}

Meu objetivo foi o de oferecer uma pequena amostragem, entre as inúmeras possibilidades de propostas de jogos corporais que podem ser feitos em sala de aula. A seleção destas categorias, Percepção, Locomoção, Partes do Corpo e Espaço, foi por considerar que elas oferecem uma base sólida para a iniciação dos alunos na linguagem do Movimento.

Os jogos listados podem ser propostos de diferentes maneiras, como já foi dito. Cada professor saberá de suas necessidades, podendo eliminar etapas sugeridas ou acrescentar outras, ocupar mais de um encontro para cada um deles, encontrar pontos de contato e juntar mais de um numa única proposta, torná-los mais simples ou sofisticados, usar música ou outro estímulo sonoro.

A intenção é provocar no professor o desejo de inventar seu próprio trabalho com os Jogos Corporais.

Lembrar de: dar o tempo necessário para que os alunos possam compreender e responder corporalmente às propostas de jogo; instruir, durante o jogo, para a elaboração de imagens que acompanhem os movimentos, enfatizando a necessidade de pensar no que faz enquanto faz. Por exemplo: ao se locomover, o aluno deve imaginar para aonde está indo. E se está indo para um lugar é porque está em um lugar e então: que lugar é esse? O que o faz se locomover? Está indo para aonde? Por quê?

Aliás, essa é uma boa pergunta para o professor de Teatro na Educação: você está indo para aonde? Por quê?

Seja para aonde for, você não está sozinho. 


\section{REFERÊNCIAS}

BRIKMAN, Lola. A linguagem do movimento corporal. 2. ed. Tradução de Beatriz A. Cannabrava. São Paulo: Summus, 1989.

CALAZANS, Julieta; CASTILHO, Jacyan; GOMES, Simone (Coord.). Dança e educação em movimento. São Paulo: Cortez, 2003.

FELDENKRAIS, Moshe. Consciência pelo movimento. Tradução de Daisy A. C. Souza. São Paulo: Summus, 1977.

LABAN, Rudolf. Dominio do movimento. Tradução de Anna Maria Barros de Vecchi e Maria Sílvia Mourão Netto. São Paulo: Summus, 1978.

STOKOE, Patricia. La expresión corporal y el adolescente. 2. ed. Buenos Aires: Barry, 1976.

STOKOE, Patricia. La expresión corporal y el niño. Buenos Aires: Ricordi, 1972. 